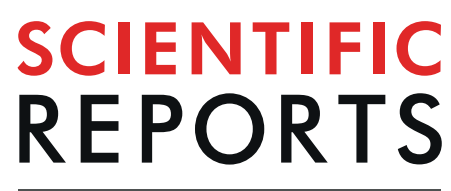

natureresearch

\title{
Taste, smell and food-related nausea and vomiting responses in hyperemesis gravidarum: A case- controlled study
}

\author{
Peng Chiong Tan $\mathbb{1 0}^{1 *}$, Balaraman Kartik ${ }^{1}$, Panjaratnam Thanendran ${ }^{2}$, Rozita Zakaria ${ }^{2}$, \\ Sandar Tin Win ${ }^{1}$ \& Siti Zawiah Omar ${ }^{1}$
}

A case-controlled study was performed to evaluate taste and smell impairment, nausea or vomiting (NV) response to taste and smell and toleration to food texture, item and cooking method in hyperemesis gravidarum patients (HG) compared to gestation-matched controls from a university hospital and primary care clinic in Malaysia. Taste strips (4 base tastes), sniff sticks (16 selected smells) and a food-related questionnaire were used. 124 participants were recruited. Taste impairment was found in $13 \%(8 / 62)$ vs. $0 \%(0 / 62) P=0.003$ and the median for correct smell identification was 5[4-6] vs. 9[7-9] P $<0.001$ in HG vs. controls. In HG, bitter was most likely (32\%) and sweet taste least likely (5\%) to provoke NV. In both arms, fish smell was most likely to provoke NV, $77 \%$ vs. $32 \% \mathrm{P}<0.001$ and peppermint smell least likely $10 \%$ vs. $0 \% \mathrm{P}=0.012$; NV response was significantly more likely for HG arm in $10 / 16$ smells. In HG, worst and best NV responses to food-texture were pasty $69 \%$ and crunchy $26 \%$; food-item, plain rice $71 \%$ and apple $16 \%$ and cooking-style, deep-frying $71 \%$ and steaming $55 \%$. HG demonstrated taste and smell impairment and increased NV responses to many tastes and smells. Crunchy sweet uncooked food (apple or watermelon) maybe best tolerated in HG.

\begin{abstract}
More than two thirds of pregnant women experienced nausea and vomiting (NVP) during early pregnancy with the more severe presentation, hyperemesis gravidarum (HG) affecting about $1.2 \%$ of pregnancies ${ }^{1}$. In $\mathrm{HG}$, nausea and vomiting is profound resulting in dehydration and starvation with hospitalization typically needed ${ }^{2,3}$.

In HG, sensitivity to sweet taste and taste threshold levels were significantly lower with a considerable alteration in taste perception ${ }^{4}$. A 3-arm study reported that women affected by HG perfomed worst in taste identification when compared to healthy pregnant women or to healthy non-pregnant women, who performed similarly ${ }^{5}$.

Two thirds of the pregnant women rated their smell sensitivity to be enhanced in pregnancy but these self-ratings were not supported by formal test scores 6 . Smell threshold has been found to be higher in first trimester pregnant women but their discrimination of smell intensity was not different ${ }^{7}$. Women in first trimester of pregnancy compared to non-pregnant controls had similar smell identification ability ${ }^{8}$ but this finding is contradicted by another study which has reported a reduction in smell identification ability in the first trimeter of pregnancy compared to women later in pregnancy and to non-pregnant healthy women ${ }^{9}$. A 3-arm study reported that HG women performed the worst in smell identification, followed by healthy pregnant women then healthy non-pregnant women who performed the best ${ }^{5}$. However, the ability by smell to differentiate safe from potentially harmful compounds does not undergo adaptation during pregnancy ${ }^{10}$. In early pregnancy, smell-induced nausea is independent of subjectively perceived intensity and appears to be due to the cognitive processing of olfactory input $^{11}$.

Dietary advice to women affected by NVP such as avoiding spicy or fatty food and preferring bland, dry, high protein food is typically based on expert opinion ${ }^{12}$. In the 12 months before pregnancy, moderate intake of water and adherence to a healthy diet that includes vegetables and fish are associated with a lower risk of developing $\mathrm{HG}^{13}$. On the other hand, high daily intake of total fat (primarily saturated fat) prepregnancy increases the risk of $\mathrm{HG}^{14}$. It is suggested that a combination of team support, individualized care, supplements created by the dietitian
\end{abstract}

${ }^{1}$ Department of Obstetrics and Gynecology, Faculty of Medicine, University of Malaya, Lembah Pantai, Kuala Lumpur, 50603, Malaysia. ${ }^{2}$ Health Clinic Putrajaya Precint 18, Pusat Pentadbiran Kerajaan Persekutuan, Putrajaya, 62602, Malaysia. *email: pctan@um.edu.my 
on the basis of patient preferences, and an adapted documented approach for patients with eating aberrations are important aspects of effective management of $\mathrm{HG}^{15}$.

We aim to experimentally evaluate taste and smell identification capablility and tolerance and to obtain questionnaire-based data on tolerated food textures, type and cooking method in HG cases compared to gestational-age matched controls to provide a basis for dietary guidance in HG.

\section{Materials and Methods}

The study was approved by the Medical Ethics Committee of University Malaya Medical Center (date of approval: 26 October 2016; reference number: 2016-99-4244) and registered with the Malaysian National Medical Research Registry (reference number: NMRR-16-2027-32724) prior to enrollment of participants. The study was conducted in University Malaya Medical Center, Kuala Lumpur and a state-funded primary care clinic in Putrajaya, Malaysia. Recruited was from December 9, 2016 to June 10,2017. The study was conducted in accordance with the Declaration of Helsinki on human experimentation. Over six months of recruitment, a total of 124 participants (62 HG cases and 62 controls) were enrolled into the study.

Study design. This was a prospective case controlled study using (i) standardized Verkauf Taste Strips (Burghart, Wedel, Germany) consisting of sweet, sour, salty and bitter of the same concentration levels, (ii) Verkauf Sniffin' Sticks (Burghart, Wedel, Germany) of 16 selected smells (banana, honey, lemon, coffee, chocolate, coconut, peppermint, sesame oil, soy sauce, menthol, clove, smoked meat, vinegar, ginger, garlic and fish) and an ad hoc food related questionnaire - Supplementary Fig. S1.

Participants. Participants were aged $\geq 18$ years with a viable, singleton, intrauterine pregnancy, $\leq 12$ weeks gestation, and enrollment Pregnancy-Unique Quantification of Emesis/Nausea (PUQE) score $\geq 9$ score for HG participants (all were hospitalized for severe nausea and vomiting of pregnancy associated with dehydration and starvation) and $\leq 6$ for controls (all had attended for routine outpatient antenatal care). The severity of NVP can be quantified using the PUQE score ${ }^{16}$. Exclusion criteria were extreme HG symptoms (inability to complete taste and smell tests), language incapacity to respond to questionnaire or pre-existing taste or olfactory disorder.

Eligible women were approached, provided with the patient information sheet and verbally counseled with regard to study participation; written informed consents were obtained from all participants. Participants' relevant demographic and clinical data were transcribed onto the Case Report Form.

Study procedures. Food questionnaire. At recruitment, participants were asked verbally if they feel more nauseous or feel like vomiting (NV) when considering eating (i) food with texture: crunchy, chewy, soft, pasty and liquid, (ii) specific food items: chicken, white fish, plain white bread, cream crackers plain rice, rice porridge, green vegetables and (iii) fruits: papaya, water melon, pineapple, banana, apple, orange, and grapes, iv) food cooked by: deep-fry, stir-fry, barbeque, steam and roast using a 5-grade Likert scale response - Supplementary Fig. S1.

Taste testing. Participants were then tested on their taste identification capability (sweet, sour, salty and bitter) using the disposable "Verkauf Taste Strips". The strips were placed on the tongue of participants for 5 seconds and up to 30 seconds were allowed for them to identify the taste (without being informed if identification was correct or not) and whether that taste provoked NV, using a 5-grade Likert scale response- Supplementary Fig. S2). Participants rinsed their mouth with plain water, paused for taste effect to dissipate before proceeding to the next taste test.

Smell testing. After completing the taste test, smell test was carried out using the 16 different odors of "Verkauf Sniffin' Sticks" - the selection of these 16 smells by investigators were based on smells familiar to our population. All participants were assessed on the same sequence of smells: banana, honey, lemon, coffee, chocolate, coconut, peppermint, sesame oil, soy sauce, menthol, clove, smoked meat, vinegar, ginger, garlic and fish (sequence based on investigators' ad hoc ranking of increasing pungence). The odor stick was held $2-3 \mathrm{~cm}$ below the nostrils of participants for 5 seconds and participants inhaled to take in the smell. Participants were allowed up to 30 seconds to identify the smell (without being informed if identification was correct or not) and whether that smell provoked NV using a 5-grade Likert scale response- Supplementary Fig. S3. A short pause for smell effect to dissipate was given before proceeding to the next smell test.

Statistical analyses. Data were entered into a statistical software package SPSS (Version 23, SPSS $\odot$ Statistics; IBM Corp., Armonk, NY). The t test was used to analyze means and distributions, the Mann-Whitney $\mathrm{U}$ test for non-normal data or ordinal data, Fisher exact test for categorical data set if any cell $<5$ and Chi Square test for larger categorical data sets. All tests were two-sided and $\mathrm{p}$ values $<0.05$ were reported as significant.

Ethics approval. Medical Ethics Committee of University Malaya Medical Center (date of approval: 26 October 2016; reference number: 2016-99-4244) and registered with the National Medical Research Registry (reference number: NMRR-16-2027-32724). Written informed consents were taken from all participants.

\section{Results}

Over a six months recruitment period, a total of 124 participants (62 HG cases and 62 controls) were enrolled into the study with no woman approached declining or too unwell (HG cases) to participate. All participants completed the study protocol.

Table 1 depicts the characteristic of study participants stratified according to HG subjects vs. pregnant controls. PUQE score ${ }^{16}$, as expected, were markedly and statistically significantly higher in the HG arm 13 [12-15] 


\begin{tabular}{|l|l|l|l|}
\hline Characteristics & $\begin{array}{l}\text { Hyperemesis } \\
(\mathbf{n = 6 2 )}\end{array}$ & $\begin{array}{l}\text { Control } \\
(\mathbf{n = 6 2})\end{array}$ & p value \\
\hline Age (years) & $29.5 \pm 4.5$ & $31.9 \pm 4.6$ & 0.003 \\
\hline Gestational Age (weeks) & $8.9 \pm 1.8$ & $8.4 \pm 1.7$ & 0.17 \\
\hline Ethnicity & & & 0.41 \\
\hline Malay & $46(74)$ & $49(79)$ & \\
\hline Chinese & $2(3)$ & $4(7)$ & \\
\hline Indian & $13(21)$ & $7(11)$ & \\
\hline Others & $1(2)$ & $2(3)$ & \\
\hline Parity & & & 0.11 \\
\hline 0 & $36(58)$ & $26(42)$ & \\
\hline 1 & $10(16)$ & $9(15)$ & \\
\hline$\geq 2$ & $16(26)$ & $27(43)$ & \\
\hline PUQE 2 Score & $\begin{array}{l}13[12-15] \\
13.0 \pm 1.8\end{array}$ & $\begin{array}{l}4[3-5] \\
4.0 \pm 1.8\end{array}$ & $<0.001$ \\
\hline
\end{tabular}

Table 1. Characteristics of study participants, stratified to hyperemesis gravidarum cases vs. control. Data expressed as number (\%), mean \pm standard and median [interquartile range]. Analyses by Student's t test for continuous data and Chi-square test for larger than $2 \times 2$ categorical datasets. $\mathrm{P}<0.05$ for all variables. ${ }^{a}$ Pregnancy-unique quantification of emesis scoring system for nausea and vomiting of pregnancy ${ }^{16}$.

vs. 4 [3-5]; $\mathrm{P}<0.001$. HG women were slightly younger. The remaining characteristics were similar across study arms.

Food questionnaire. In HG participants, crunchy food texture was reportedly best tolerated with $26 \%$ $(16 / 62)$ stated that it provoked NV, whilst pasty texture had the worst result with 69\% (43/62) responded that it provoked NV when they considered eating food with that texture. Among food items, plain rice was worst with NV rate in $71 \%(44 / 62)$ and plain white bread was best at $31 \%(19 / 62)$. Amongst the seven fruits listed, apple fared best with provoked NV rate of only $16 \%(10 / 62)$ and pineapple worst at $57 \%$ (35/62). Fruits generally fared well with 5 of the 7 listed occupying the top 5 best tolerated positions amongst the 14 selected food items. Cooked food generally fared poorly in NV provocation rates; steam cooking despite coming in with top tolerance, 55\% (34/62) still responded negatively and deep frying had the worst response with $71 \%$ (44/62) NV rate amongst HG participants. Controls consistently do not expressed the NV response to any questionnaire items. In every comparison made, HG cases performed statistically significantly worst in NV rates than controls (Table 2).

Taste tests. In the taste tests (Table 3), controls could invariably (62/62: 100\%) identify the basic tastes of sweet, sour, salty and bitter. Controls also invariably (62/62: 100\%) did not respond with NV after any taste exposures. HG women were significantly worse than controls in identifying salty taste $90 \%(56 / 62)$ vs. $100 \%(62 / 62)$ $\mathrm{P}=0.03$. Although a few ( 2 to 4$) \mathrm{HG}$ women were not able to correctly identify taste in a given category, the difference was not significantly at the $5 \%$ level for sweet, sour and bitter tastes for HG case-control comparisons. There was taste impairment (at least 1 taste test error in 4) in 14\% (9/62) of HG women vs 0\% (0/62) of controls $\mathrm{P}=0.003$. In HG patients, bitter taste was most likely $32 \%(20 / 62)$, followed by sour $23 \%(14 / 61)$ then salty $16 \%$ $(10 / 62)$ and lastly sweet taste the least likely $5 \%(3 / 62)$ to provoke NV response during the taste test (Table 3). From a maximum score of 4 , the HG women's cumulative score (mean \pm standard deviation) was $3.76 \pm 0.67$ compared to $4 \pm 0.0, \mathrm{P}=0.006$ for controls in number of tastes correctly identified. The $\mathrm{NV}$ response rate were significantly higher in the HG arm for bitter, sour and salty but not for sweet when compared to controls.

Smell tests. In smell identification tests (Table 4) on the 16 smells selected for the study, HG cases performed significantly worse than controls for 10 smells namely coconut, sesame, menthol, chocolate, ginger, peppermint, lemon, garlic, banana and fish compared to controls. From a maximum cumulative score of 16, the HG group scored a median 5 [IQR 4-6] compared to 9 [IQR 7-9] for controls, $\mathrm{P}<0.001$ in number of smells correctly identified; no woman in the HG scored $>9$ correct smell identification (Fig. 1). HG cases compared to controls were more likely to have significantly higher NV response in all 16 smells tested. In HG cases, fish, garlic and sesame oil smells were the most likely to provoke NV responses with rates of 77\% (48/62), 63\% (39/62) and 58\% (36/62) whilst peppermint, lemon and banana smells were best tolerated with rates of $10 \%(6 / 62), 15 \%(9 / 62)$ and $15 \%$ $(9 / 62)$ respectively. In controls, fish, smoked meat and garlic smells ranked highest to provoke NV and peppermint, lemon and banana smells rated $0 \% \mathrm{NV}$ response rate; there was very close symmetry of $\mathrm{HG}$ and controls in NV response order to 16 smells tested (Table 4).

\section{Discussion}

In our experiment using taste pad and smell stick testing, we find impairment (14\% vs. 0\%) of taste and significantly lower cumulative (out of 16 smells tested) correct smell identification score 5 [IQR 4-6] vs. 9 [IQR 7-9] in the HG patients compared to early pregnancy controls. Taste identification deficit to sweet, sour, salty and bitter between HG cases and controls were more subtle with $86 \%$ of HG cases maintaining intact taste identification capability to all 4 basic tastes compared to the larger smell identification deficit for the 16 selected smells in HG arm. 


\begin{tabular}{|c|c|c|c|c|c|}
\hline & \multicolumn{2}{|c|}{ Hyperemesis $(n=62)$} & \multicolumn{2}{|c|}{ Control $(n=62)$} & \multirow[b]{2}{*}{ p value } \\
\hline & Agree $^{a}$ & Do not Agree ${ }^{a}$ & Agree $^{a}$ & $\begin{array}{l}\text { Do not } \\
\text { Agree }^{\mathrm{a}}\end{array}$ & \\
\hline \multicolumn{6}{|l|}{ Food texture $^{a}$} \\
\hline 1. Pasty & $43(69)$ & $19(31)$ & $0(0)$ & $62(100)$ & $<0.001$ \\
\hline 2. Liquid & $29(47)$ & $33(53)$ & $0(0)$ & $62(100)$ & $<0.001$ \\
\hline 3. Chewy & $24(39)$ & $38(61)$ & $0(0)$ & $62(100)$ & $<0.001$ \\
\hline 4. Soft & $24(39)$ & $38(61)$ & $0(0)$ & $62(100)$ & $<0.001$ \\
\hline 5. Crunchy & $16(26)$ & $46(74)$ & $0(0)$ & $62(100)$ & $<0.001$ \\
\hline \multicolumn{6}{|l|}{ Food $_{\text {item }}{ }^{b}$} \\
\hline 1. Plain Rice & $44(71)$ & $18(29)$ & $0(0)$ & $62(100)$ & $<0.001$ \\
\hline 2. Pineapple & $35(57)$ & $27(43)$ & $0(0)$ & $62(100)$ & $<0.001$ \\
\hline 3. White Fish & $34(55)$ & $28(45)$ & $0(0)$ & $62(100)$ & $<0.001$ \\
\hline 4. Chicken & $32(52)$ & $30(48)$ & $0(0)$ & $62(100)$ & $<0.001$ \\
\hline 5. Rice Porridge & $26(42)$ & $26(58)$ & $0(0)$ & $62(100)$ & $<0.001$ \\
\hline 6. Papaya & $26(42)$ & $36(58)$ & $0(0)$ & $62(100)$ & $<0.001$ \\
\hline 7. Cream Crackers & $25(40)$ & $37(60)$ & $0(0)$ & $62(100)$ & $<0.001$ \\
\hline 8. Green Vegetables & $25(40)$ & $37(60)$ & $0(0)$ & $62(100)$ & $<0.001$ \\
\hline 9. Plain White Bread & $19(31)$ & $43(69)$ & $0(0)$ & $62(100)$ & $<0.001$ \\
\hline 10. Grapes & $19(31)$ & $43(69)$ & $0(0)$ & $62(100)$ & $<0.001$ \\
\hline 11. Banana & $17(27)$ & $45(73)$ & $0(0)$ & $62(100)$ & $<0.001$ \\
\hline 12. Oranges & $14(23)$ & $48(77)$ & $0(0)$ & $62(100)$ & $<0.001$ \\
\hline 13. Watermelon & $13(21)$ & $49(79)$ & $0(0)$ & $62(100)$ & $<0.001$ \\
\hline 14. Apples & $10(16)$ & $52(84)$ & $0(0)$ & $62(100)$ & 0.001 \\
\hline \multicolumn{6}{|l|}{ Cooking method $^{c}$} \\
\hline Deep Fried & $44(71)$ & $18(29)$ & $0(0)$ & $62(100)$ & $<0.001$ \\
\hline Barbeque & $41(66)$ & $21(34)$ & $0(0)$ & $62(100)$ & $<0.001$ \\
\hline Roasted & $38(61)$ & $24(39)$ & $0(0)$ & $62(100)$ & $<0.001$ \\
\hline Stir Fried & $36(58)$ & $26(42)$ & $0(0)$ & $62(100)$ & $<0.001$ \\
\hline Steamed & $34(55)$ & $28(45)$ & $0(0)$ & $62(100)$ & $<0.001$ \\
\hline
\end{tabular}

Table 2. Likert scale response of feeling nauseous and vomiting to questionnaire item. Data displayed as number (\%), analysis by Chi Square test. ${ }^{a}$ Recategorisation of Likert scale responses: Agree includes strongly or somewhat agree, the responses: Do not agree includes neither agree nor disagree, somewhat disagree and strongly disagree responses. ${ }^{b}$ The food texture order as tabulated is from worst to best response in HG women. ${ }^{\mathrm{c}}$ The food and fruit item order as tabulated is from worst to best response in HG women. ${ }^{\mathrm{d}}$ The cooking method order as tabulated is from worst to best response in HG women.

In a 3-arm study comprising HG affected women, healthy pregnant women and healthy non-pregnant women, with 4 base tastes assessed using taste sprays, taste identification scores were respectively $3.4 \pm 0.9$ vs. $3.9 \pm 0.1$ vs. $3.9 \pm 0.1 \mathrm{p}=0.003^{5}$ whereas in our study we used individual taste strips with scores of $3.76 \pm 0.67$ (HG women) compared to $4 \pm 0.0$ (early pregnancy controls), $\mathrm{P}=0.006$ : these findings were consistent with each other in demonstrating a small reduction in taste identification ability in HG. With 12 odors assessed using Sniffin' Sticks test battery (Burghart, Wedel, Germany) as similarly used in our study, smell identification scores were respectively $9.1 \pm 1.6$ ( $\mathrm{HG}$ women) vs $9.3 \pm 1.4$ (healthy pregnant women) vs $10.1 \pm 1.3 \mathrm{P}=0.03$ (healthy non pregnant women $)^{5}$ compared to our finding of 5 [IQR 4-6] (HG women) vs 9 [IQR 7-9] (early pregnancy control) $\mathrm{P}<0.001$ of 16 smells tested (there were 6 overlap in the selected smells between their study and ours); our finding showed a much more marked reduction in odor identification ability in $\mathrm{HG}$ affected women versus early pregnancy controls compared to the marginal difference $(9.1 / 12$ vs $9.3 / 12)$ between these 2 groups in their study.

Sweet is the best tolerated taste by the HG group with only $5 \%$ finding it disagreeable, the only taste or smell where NV response rate is not significantly different to controls. On the other hand, universally in controls no taste test provoked any NV response. Women with NVP are characterized by high intakes of carbohydrates and added sugar ${ }^{17}$ and according to a multiethnic South African study pregnant women have pronounced craving for sweet foods ${ }^{18}$, our data that HG women find sweet taste least likely to provoke NV is consistent with a consumption pattern that favored added sugar in NVP women and craving for sweet foods in pregnancy.

The smell of garlic and sesame oil for instance had the largest absolute difference of $56 \%$ in NV response rates of the 16 smells tested between HG cases to controls. Peppermint is the best tolerated smell in HG women with only $10 \%$ reporting NV response after test exposure compared to $0 \%$ in controls. There was close symmetry in the smell-provoked NV response league table for HG and controls, with good matches at the top and bottom of the respective rankings but vinegar and honey smells are qualitative standouts; $52 \%$ and $48 \% \mathrm{NV}$ response in HG compared to $0 \%$ and $0 \% \mathrm{NV}$ response in controls (Table 4). It has been reported that pregnant women rated the odors of 'rum', 'cigarette' and 'coffee' as more aversive than non-pregnant women ${ }^{19}$; in our controls coffee smell had $0 \%$ provoke NV response rate and in HG coffee had a relatively low $18 \% \mathrm{NV}$ response rate. Meat, fish, coffee 


\begin{tabular}{|c|c|c|c|c|c|c|}
\hline \multicolumn{7}{|c|}{ Identification of taste using Verkauf Taste Test Strips } \\
\hline \multirow[b]{2}{*}{ Taste $^{\mathrm{a}}$} & \multicolumn{2}{|c|}{ Hyperemesis $(n=62)$} & \multicolumn{2}{|c|}{ Control $(n=62)$} & & \multirow[b]{2}{*}{ p value } \\
\hline & Correct & Incorrect & Correct & Incorrect & & \\
\hline Sweet & $59(95)$ & $3(5)$ & $62(100)$ & $0(0)$ & & 0.244 \\
\hline Sour & $60(97)$ & $2(3)$ & $62(100)$ & $0(0)$ & & 0.496 \\
\hline Salty & $56(90)$ & $6(10)$ & $62(100)$ & $0(0)$ & & 0.028 \\
\hline Bitter & $58(94)$ & $4(7)$ & $62(100)$ & $0(0)$ & & 0.119 \\
\hline \multicolumn{7}{|c|}{ Likert scale response of feeling nauseous \& vomiting to evaluated taste } \\
\hline Taste $^{\mathrm{b}}$ & Agree $^{c}$ & Do not Agree $^{\mathrm{c}}$ & Agree $^{c}$ & Do not Agree $^{\mathrm{c}}$ & & \\
\hline Bitter & $20(32)$ & $42(68)$ & $62(100)$ & $0(0)$ & & $<0.001$ \\
\hline Sour & $14(23)$ & $48(77)$ & $62(100)$ & $0(0)$ & & 0.0005 \\
\hline Salty & $10(16)$ & $52(84)$ & $62(100)$ & $0(0)$ & & 0.001 \\
\hline Sweet & $3(5)$ & $59(95)$ & $62(100)$ & $0(0)$ & & 0.244 \\
\hline \multicolumn{7}{|c|}{ Composite score of taste capability of hyperemesis gravidarum cases vs. controls } \\
\hline & \multicolumn{5}{|c|}{ Correct identification of the four tastes ${ }^{\mathrm{d}}$ evaluated } & \\
\hline Group & None & $1 / 4$ & $2 / 4$ & $3 / 4$ & All 4 & \\
\hline $\begin{array}{l}\text { Hyperemesis } \\
\mathrm{n}=62\end{array}$ & $0(0)$ & $2(3)$ & $2(3)$ & $5(8)$ & $53(86)$ & 0.003 \\
\hline $\begin{array}{l}\text { Control } \\
\mathrm{n}=62\end{array}$ & $0(0)$ & $0(0)$ & $0(0)$ & $0(0)$ & $62(100)$ & \\
\hline
\end{tabular}

Table 3. Taste identification capability (using Verkauf Taste Test Strips) and nausea-vomiting response to evaluated taste in hyperemesis gravidarum cases vs. controls. Data displayed as number (\%), analysis by Chi Square test. ${ }^{\text {aT }}$ The taste order as tabulated is according to the test sequence on participants. ${ }^{\text {b The taste order }}$ as tabulated is from worst to best response in HG women. ${ }^{c}$ Recategorisation of Likert scale responses: Agree includes strongly or somewhat agree, the responses: Do not agree includes neither agree nor disagree, somewhat disagree and strongly disagree responses. ${ }^{\mathrm{d} S}$ weet, sour, salty and bitter. ${ }^{\mathrm{e}} 2 \times 5$ Fisher exact test.

and fatty foods, are foods most often avoided in pregnancy according to a multiethnic South African study ${ }^{18}$, consistent with the high ranked position in our NV response table of fish (77\%) and smoked meat odors (45\%) for HG women but our controls also ranked these smells (32\% and 10\% respectively) as NV inducing (Table 4) albeit at a diminished rate. Ginger taken orally has been shown to help nausea and vomiting in pregnancy ${ }^{20}$; ginger smell had a low NV response rate of $16 \%$ and $0 \%$ for HG and controls respectively.

In the HG group, the magnitude of NV response to many ( 8 of 16 had $37 \%$ or higher NV response) smells were larger than to the 4 base tastes (bitter with worst $32 \%$ NV response) suggesting that the smell more than taste of food and drink may have the greater potential to be the initiator and driver of nausea and emesis in HG.

The cause or effect of taste and smell deficits to HG cannot be established by this cross-sectional study; we do not have the longitudinal data to evaluate if these deficits predate or dissipate with recovery from HG.

In the questionnaire-based component of our study, crunchy (26\%) food texture is least likely to evoke feel more nauseous or feel like vomiting responses and pasty texture (69\%) the most likely. Controls did not have a $\mathrm{NV}$ response to any of the five foods texture evaluated.

Of the 14 selected common food items, plain rice had the highest (71\%) NV in HG cases compared to $0 \%$ in controls. The poor response to plain rice may be due to its ethno-cultural symbolism as "food" in our society and probably the rejection of food conditioned by acute HG. Rice porridge, broadly seen as a recuperative food during illness in our social setting had a mid-ranking position in our food item league table with $42 \% \mathrm{NV}$ response. Aversions to staple foods is reportedly common in pregnancy ${ }^{21}$ and our finding is consistent with an exaggerated response in $\mathrm{HG}$.

Fruits occupy the best 5 positions (out of 7 fruits listed); apple was in best position with only a $16 \%$ NVP response rate in HG cases. Pineapple's and to a lesser extent papaya's poor rating amongst fruits might be accounted for by folk belief that they induce miscarriage with that concern amplified by vulnerability arising from HG. None of the 14 food items evaluated evoked NV sensation in controls.

Contemplating eating steamed food had the lowest NV response rate at 55\%; deep-fried of food had the highest at $71 \%$ in HG. With all five cooking methods, a majority in $\mathrm{HG}$ arm expressed a NV response suggesting that the thought of eating cooked food was problematic. None of the five cooking methods evoked NV sensation in controls.

There was a confluence of findings that fruity (lemon, banana and coconut) smells were better tolerated and fruits like apples, watermelon, oranges and bananas least likely to provoke NV sensations when their eating was contemplated. Food texture, cooking method and food item in terms of tolerance or preference were likely influenced by culinary heritage. However, preference for and tolerance to fresh fruits are quite likely to cut across the ethno-cultural and culinary boundaries. The fruits selected for our questionnaire are widely consumed. We believe our finding that generally favored fresh fruits in HG could be generalizable.

In pregnant women in Tanzania, fruits like mangos and oranges are craved and rice and fish avoided usually for no particular reason ${ }^{22}$. Our data for HG women finds oranges to be well tolerated and rice and fish amongst the worst tolerated reflecting a degree of symmetry with the Tanzanian data. Increasing severity of nausea was 


\begin{tabular}{|c|c|c|c|c|c|c|}
\hline \multicolumn{7}{|c|}{ Identification of Selected Common Food smell using Verkauf Sniffing Sticks } \\
\hline \multirow[b]{2}{*}{ Smell } & \multicolumn{2}{|c|}{ Hyperemesis $(n=62)$} & \multicolumn{2}{|c|}{ Control $(n=62)$} & \multirow[b]{2}{*}{ RR $(95 \%$ CI $)$} & \multirow[b]{2}{*}{ p value } \\
\hline & Incorrect & Correct & Incorrect & Correct & & \\
\hline Fish & $20(32)$ & $42(68)$ & $0(0)$ & $62(100)$ & - & $<0.001$ \\
\hline Banana & $42(68)$ & $20(32)$ & $2(3)$ & $60(97)$ & $21.0(5.3-83.0)$ & $<0.001$ \\
\hline Garlic & $32(52)$ & $30(48)$ & $2(3)$ & $60(97)$ & $16.0(4.0-64.0)$ & $<0.001$ \\
\hline Lemon & $39(63)$ & $23(37)$ & $7(11)$ & $55(89)$ & $5.6(2.7-11.5)$ & $<0.001$ \\
\hline Coffee & $7(11)$ & $55(89)$ & $2(3)$ & $60(97)$ & $3.5(1.0-16.2)$ & 0.16 \\
\hline Peppermint & $15(24)$ & $47(76)$ & $5(8)$ & $57(92)$ & $3.0(1.2-7.7)$ & 0.02 \\
\hline Ginger & $53(86)$ & $9(14)$ & $20(32)$ & $42(68)$ & $2.7(1.8-3.9)$ & $<0.001$ \\
\hline Chocolate & $45(73)$ & $17(27)$ & $21(34)$ & $41(66)$ & $2.1(1.5-3.1)$ & $<0.001$ \\
\hline Menthol & $43(70)$ & $19(30)$ & $21(34)$ & $41(66)$ & $2.0(1.4-3.0)$ & $<0.001$ \\
\hline Vinegar & $51(82)$ & $11(18)$ & $44(71)$ & $18(29)$ & $1.2(1.0-1.4)$ & 0.14 \\
\hline Sesame Oil & $59(95)$ & $3(5)$ & $51(82)$ & $11(18)$ & $1.2(1.0-1.3)$ & 0.04 \\
\hline Coconut & $57(92)$ & $5(8)$ & $47(76)$ & $15(24)$ & $1.2(1.0-1.4)$ & 0.02 \\
\hline Smoked Meat & $60(97)$ & $2(3)$ & $56(90)$ & $6(10)$ & $1.1(1.0-1.2)$ & 0.27 \\
\hline Clove & $52(84)$ & $10(16)$ & $55(89)$ & $7(11)$ & $1.0(1.0-1.1)$ & 0.43 \\
\hline Soy Sauce & $58(93)$ & $4(7)$ & $56(90)$ & $6(10)$ & $1.0(1.0-1.2)$ & 0.74 \\
\hline Honey & $60(97)$ & $2(3)$ & $59(95)$ & $3(5)$ & $1.0(1.0-1.1)$ & 1.0 \\
\hline \multicolumn{7}{|c|}{ Likert scale response of feeling nauseous \& vomiting to the evaluated smell } \\
\hline & \multicolumn{2}{|c|}{ Hyperemesis $(n=62)$} & \multicolumn{2}{|c|}{ Control $(n=62)$} & & \\
\hline Smell & Agree $^{\mathrm{c}}$ & $\begin{array}{l}\text { Do not } \\
\text { Agree }^{c}\end{array}$ & Agree $^{c}$ & $\begin{array}{l}\text { Do not } \\
\text { Agree }^{c}\end{array}$ & & \\
\hline Fish & $48(77)$ & $14(23)$ & $20(32)$ & $42(68)$ & $0.3(0.2-0.5)$ & $<0.001$ \\
\hline Garlic & $39(63)$ & $23(37)$ & $4(7)$ & $58(93)$ & $0.4(0.3-0.6)$ & $<0.001$ \\
\hline Sesame Oil & $36(58)$ & $26(42)$ & $1(2)$ & $61(98)$ & $0.4(0.3-0.6)$ & $<0.001$ \\
\hline Vinegar & $32(52)$ & $30(48)$ & $0(0)$ & $62(100)$ & $0.5(0.4-0.6)$ & $<0.001$ \\
\hline Honey & $30(48)$ & $32(52)$ & $0(0)$ & $62(100)$ & $0.5(0.4-0.7)$ & $<0.001$ \\
\hline Smoked Meat & $28(45)$ & $34(55)$ & $6(10)$ & $56(90)$ & $0.6(0.5-0.8)$ & $<0.001$ \\
\hline Soy Sauce & $27(44)$ & $35(56)$ & $1(2)$ & $61(98)$ & $0.6(0.5-0.7)$ & $<0.001$ \\
\hline Clove & $23(37)$ & $39(63)$ & $2(3)$ & $60(97)$ & $0.7(0.5-0.8)$ & $<0.001$ \\
\hline Chocolate & $14(23)$ & $48(77)$ & $0(0)$ & $62(100)$ & $0.8(0.7-0.9)$ & $<0.001$ \\
\hline Coffee & $11(18)$ & $51(82)$ & $0(0)$ & $62(100)$ & $0.8(0.7-0.9)$ & 0.01 \\
\hline Ginger & $10(16)$ & $52(84)$ & $0(0)$ & $62(100)$ & $0.8(0.8-0.9)$ & 0.01 \\
\hline Menthol & $10(16)$ & $52(84)$ & $0(0)$ & $62(100)$ & $0.8(0.8-0.9)$ & 0.01 \\
\hline Coconut & $10(16)$ & $52(84)$ & $0(0)$ & $62(100)$ & $0.8(0.8-0.9)$ & 0.01 \\
\hline Banana & $9(15)$ & $53(85)$ & $0(0)$ & $62(100)$ & $0.9(0.8-0.9)$ & 0.02 \\
\hline Lemon & $9(15)$ & $53(85)$ & $0(0)$ & $62(100)$ & $0.8(0.7-0.9)$ & 0.02 \\
\hline Peppermint & $6(10)$ & $56(90)$ & $0(0)$ & $62(100)$ & $0.9(0.8-1.0)$ & 0.012 \\
\hline
\end{tabular}

Table 4. Smell Testing capability (using Verkauf Sniffin Sticks) and nausea-vomiting response to evaluated smell in hyperemesis gravidarum cases vs. controls. Data displayed as number (\%), analysis by Chi Square test and $\mathrm{P}<0.05$ for all variables. ${ }^{\mathrm{a}}$ The smell order as tabulated is from worst to best performance as stratified by relative risk for incorrect smell identification comparing HG with controls. ${ }^{\text {b}}$ The smell order as tabulated from worst to response in HG women. ${ }^{c}$ Recategorisation of Likert scale responses: Agree includes strongly or somewhat agree, the responses: Do not agree includes neither agree nor disagree, somewhat disagree and strongly disagree responses.

also associated with decreasing prudent diet score from before to early pregnancy, such that women with severe nausea had prudent diet scores 0.29 SDs lower than those with no nausea $(\mathrm{P}<0.001)^{23}$.

Strengths and limitations. This original study provided cross sectional data on the association of taste and smell defects in HG compared to controls. The selection of smells for our test panel of 16 is eclectic but commonly encountered in our population. This smells panel may restrict generalizability to other HG populations. Although there is some overlap, our test panel of smell did not dovetail perfectly with the food items in the questionnaire section of our study; possibly a missed opportunity to corroborate across the different sections of this study.

\section{Conclusion}

There is a deficiency in taste and smell identification in women hospitalized for HG. Women affected by HG were also hypersensitive to taste (except sweet taste) and particularly smell stimulation with significantly more women reporting NV when experimentally exposed compared to gestation-matched controls. Sweet, crunchy 


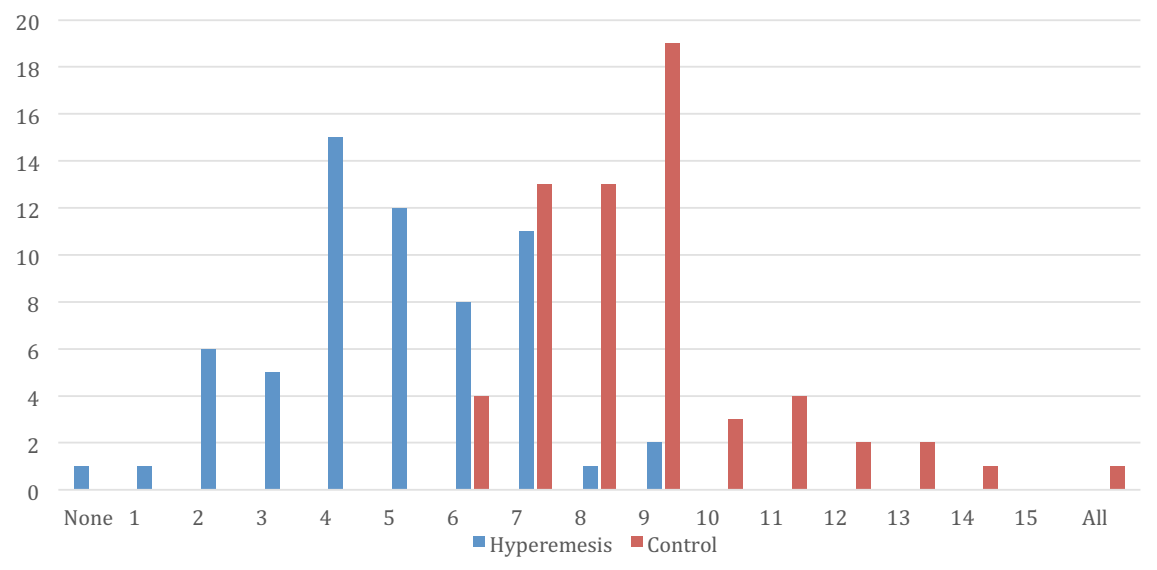

Figure 1. Hyperemesis Gravidarum Compared to Controls: Number of Participants vs. Their Score of Correct Smell Identification. Identification of 16 selected smells (test sequence: banana, honey, lemon, coffee, chocolate, coconut, peppermint, soya sauce, sesame oil, menthol, clove, smoked meat, vinegar, ginger, garlic and fish) The median score [minimum 0 to maximum 16] of smells correctly identified for Hyperemesis Gravidarum group is 5 [IQR 4-6] compared to Control group which is 9 [IQR 7-9] $\mathrm{p}<0.001$.

and uncooked (fresh) food characteristics were favored by HG women, and these characteristics dovetailed neatly to apple and watermelon being rated as best tolerated food when their eating is contemplated.

\section{Data availability}

All data generated or analyzed during this study are included in this published article (and its Supplementary information files).

Received: 7 June 2019; Accepted: 19 February 2020;

Published online: 10 March 2020

\section{References}

1. Einarson, T. R., Piwko, C. \& Koren, G. Prevalence of nausea and vomiting of pregnancy in the USA: a meta analysis. J. Popul. Ther. Clin. Pharmacol. 20, e163-170 (2013).

2. Verberg, M. F., Gillott, D. J., Al-Fardan, N. \& Grudzinskas, J. G. Hyperemesis gravidarum, a literature review. Hum. Reprod. Update 11, 527-539, https://doi.org/10.1093/humupd/dmi021 (2005).

3. Tan, P. C. \& Omar, S. Z. Contemporary approaches to hyperemesis during pregnancy. Curr. Opin. Obstet. Gynecol. 23, 87-93, https:// doi.org/10.1097/GCO.0b013e328342d208 (2011).

4. Mizumoto, Y. et al. Studies on hypogeusia in hyperemesis gravidarum. Nihon Sanka Fujinka Gakkai Zasshi 46, 35-41 (1994).

5. Yasar, M., Sagit, M., Zeki Uludag, S. \& Ozcan, I. Does odor and taste identification change during hyperemesis gravidarum? Med. Glas. 13, 50-55, https://doi.org/10.17392/833-16 (2016).

6. Cameron, E. L. Measures of human olfactory perception during pregnancy. Chem. Senses 32, 775-782, https://doi.org/10.1093/ chemse/bjm045 (2007).

7. Laska, M., Koch, B., Heid, B. \& Hudson, R. Failure to demonstrate systematic changes in olfactory perception in the course of pregnancy: a longitudinal study. Chem. Senses 21, 567-571 (1996).

8. Ochsenbein-Kolble, N., von Mering, R., Zimmermann, R. \& Hummel, T. Changes in olfactory function in pregnancy and postpartum. Int. J. Gynaecol. Obstet. 97, 10-14, https://doi.org/10.1016/j.ijgo.2006.12.009 (2007).

9. Simsek, G. et al. Marked changes in olfactory perception during early pregnancy: a prospective case-control study. Eur. Arch. Otorhinolaryngol. 272, 627-630, https://doi.org/10.1007/s00405-014-3147-7 (2015).

10. Swallow, B. L. et al. Smell perception during early pregnancy: no evidence of an adaptive mechanism. BJOG 112, 57-62, https://doi. org/10.1111/j.1471-0528.2004.00327.x (2005).

11. Hummel, T., von Mering, R., Huch, R. \& Kolble, N. Olfactory modulation of nausea during early pregnancy? BJOG 109, 1394-1397 (2002).

12. American College of, O. \& Gynecology. ACOG (American College of Obstetrics and Gynecology) Practice Bulletin: nausea and vomiting of pregnancy. Obstet. Gynecol. 103, 803-814 (2004).

13. Haugen, M. et al. Diet before pregnancy and the risk of hyperemesis gravidarum. Br. J. Nutr. 106, 596-602, https://doi.org/10.1017/ S0007114511000675 (2011).

14. Signorello, L. B., Harlow, B. L., Wang, S. \& Erick, M. A. Saturated fat intake and the risk of severe hyperemesis gravidarum. Epidemiol. 9, 636-640 (1998).

15. Schulman, P. K. Hyperemesis gravidarum: an approach to the nutritional aspects of care. J. Am. Diet. Assoc. 80, 577-578 (1982).

16. Koren, G. et al. Motherisk-PUQE (pregnancy-unique quantification of emesis and nausea) scoring system for nausea and vomiting of pregnancy. Am. J. Obstet. Gynecol. 186, S228-231 (2002).

17. Chortatos, A. et al. Nausea and vomiting in pregnancy: associations with maternal gestational diet and lifestyle factors in the Norwegian Mother and Child Cohort Study. BJOG 120, 1642-1653, https://doi.org/10.1111/1471-0528.12406 (2013).

18. Walker, A. R., Walker, B. F., Jones, J., Verardi, M. \& Walker, C. Nausea and vomiting and dietary cravings and aversions during pregnancy in South African women. Br. J. Obstet. Gynaecol. 92, 484-489, https://doi.org/10.1111/j.1471-0528.1985.tb01353.x (1985).

19. Kolble, N., Hummel, T., von Mering, R., Huch, A. \& Huch, R. Gustatory and olfactory function in the first trimester of pregnancy. Eur. J. Obstet. Gynecol. Reprod. Biol. 99, 179-183 (2001). 
20. Vutyavanich, T., Kraisarin, T. \& Ruangsri, R. Ginger for nausea and vomiting in pregnancy: randomized, double-masked, placebocontrolled trial. Obstet. Gynecol. 97, 577-582 (2001).

21. Placek, C. D., Madhivanan, P. \& Hagen, E. H. Innate food aversions and culturally transmitted food taboos in pregnant women in rural southwest India: separate systems to protect the fetus? Evol. Hum. Behav. 38, 714-728, https://doi.org/10.1016/j. evolhumbehav.2017.08.001 (2017).

22. Nyaruhucha, C. N. Food cravings, aversions and pica among pregnant women in Dar es Salaam, Tanzania. Tanzan. J. Health Res. 11, 29-34 (2009).

23. Crozier, S. R. et al. Nausea and vomiting in early pregnancy: Effects on food intake and diet quality. Matern Child Nutr 13, https:// doi.org/10.1111/mcn.12389 (2017).

\section{Acknowledgements}

We thank the women who participated in the study and all care providers for their contribution to this study. This study is self-funded by the investigators and assisted by the internal resources of the Department of Obstetrics and Gynecology, University of Malaya.

\section{Author contributions}

All authors (P.C.T., B.K., P.T., R.Z., S.T.W. and S.Z.O.) contributed to elements of study design. P.C.T. conceptualized and had main responsibility for study design. B.K. ran the study, B.K. and P.T. collected the data. P.C.T. and S.T.W. did the primary data analyses and data interpretation. P.C.T., S.T.W. and B.K. co-drafted the manuscript. P.T., R.Z. and S.Z.O. provide critique to refine the manuscript. All authors have approved the final version of this manuscript and assert responsibility over the article. The corresponding author attests that the listed co-authors meet authorship criteria.

\section{Competing interests}

The authors declare no competing interests.

\section{Additional information}

Supplementary information is available for this paper at https://doi.org/10.1038/s41598-020-61114-y.

Correspondence and requests for materials should be addressed to P.C.T.

Reprints and permissions information is available at www.nature.com/reprints.

Publisher's note Springer Nature remains neutral with regard to jurisdictional claims in published maps and institutional affiliations.

(c) (i) Open Access This article is licensed under a Creative Commons Attribution 4.0 International License, which permits use, sharing, adaptation, distribution and reproduction in any medium or format, as long as you give appropriate credit to the original author(s) and the source, provide a link to the Creative Commons license, and indicate if changes were made. The images or other third party material in this article are included in the article's Creative Commons license, unless indicated otherwise in a credit line to the material. If material is not included in the article's Creative Commons license and your intended use is not permitted by statutory regulation or exceeds the permitted use, you will need to obtain permission directly from the copyright holder. To view a copy of this license, visit http://creativecommons.org/licenses/by/4.0/.

(c) The Author(s) 2020 